\title{
Review \\ Plasmonic Metasurfaces for Medical Diagnosis Applications: A Review
}

\author{
Zhenbiao Wang ${ }^{1,2}$, Junjie Chen ${ }^{3}$, Sayed Ali Khan ${ }^{1}$, Fajun Li ${ }^{1}$, Jiaqing Shen ${ }^{1}$, Qilin Duan ${ }^{1}$, Xueying Liu ${ }^{1}$ \\ and Jinfeng Zhu 1,2,* \\ 1 Key Laboratory of Electromagnetic Wave Science and Detection Technology, \\ Institute of Electromagnetics and Acoustics, Xiamen University, Xiamen 361005, China; \\ 34320201150180@stu.xmu.edu.cn (Z.W.); sayedali@szu.edu.cn (S.A.K.); \\ 34320191150185@stu.xmu.edu.cn (F.L.); 34320210155961@stu.xmu.edu.cn (J.S.); \\ duanqilin@stu.xmu.edu.cn (Q.D.); 34320190153851@stu.xmu.edu.cn (X.L.) \\ 2 State Key Laboratory of Applied Optics, Changchun Institute of Optics, Fine Mechanics and Physics, \\ Chinese Academy of Sciences, Changchun 130033, China \\ 3 Analysis and Measurement Center, School of Pharmaceutical Science, Xiamen University, \\ Xiamen 361003, China; chenjunjie@xmu.edu.cn \\ * Correspondence: jfzhu@xmu.edu.cn
}

check for updates

Citation: Wang, Z.; Chen, J.; Khan, S.A.; Li, F.; Shen, J.; Duan, Q.; Liu, X.; Zhu, J. Plasmonic Metasurfaces for Medical Diagnosis Applications: A Review. Sensors 2022, 22, 133. https://doi.org/10.3390/s22010133 Academic Editor: Nikolay Kazanskiy

Received: 1 December 2021 Accepted: 23 December 2021 Published: 25 December 2021

Publisher's Note: MDPI stays neutral with regard to jurisdictional claims in published maps and institutional affiliations.

Copyright: (C) 2021 by the authors. Licensee MDPI, Basel, Switzerland. This article is an open access article distributed under the terms and conditions of the Creative Commons Attribution (CC BY) license (https:// creativecommons.org/licenses/by/ $4.0 /)$.

\begin{abstract}
Plasmonic metasurfaces have been widely used in biosensing to improve the interaction between light and biomolecules through the effects of near-field confinement. When paired with biofunctionalization, plasmonic metasurface sensing is considered as a viable strategy for improving biomarker detection technologies. In this review, we enumerate the fundamental mechanism of plasmonic metasurfaces sensing and present their detection in human tumors and COVID-19. The advantages of rapid sampling, streamlined processes, high sensitivity, and easy accessibility are highlighted compared with traditional detection techniques. This review is looking forward to assisting scientists in advancing research and developing a new generation of multifunctional biosensors.
\end{abstract}

Keywords: plasmonic metasurfaces; biosensing; cancer; COVID-19

\section{Introduction}

Since wood observed the plasmon phenomenon on the subwavelength metal grating in 1902, the development of plasmon has made rapid progress in the last hundred years [1-9]. Surface plasmon resonance (SPR) is a collective electronic oscillation phenomenon, which could be classified into two main forms, as surface plasmon polarization (SPP) and localized surface plasmon resonance (LSPR), by their different excitation ways [10]. SPP is commonly produced by shining plane-polarized light onto a continuous metal surface, which can break the diffraction limit and improve the ability to manipulate light on the sub-wavelength scale, making it a promising candidate for the next generation of ultra-miniature integrated photonic circuits and highly sensitive biosensors for information processing [11,12]. The LSPR, on the other hand, is the collective oscillation of electrons at the interface of metal nanoparticles (NPs) irradiated by the excited light of specific frequencies. Due to their sensitivities to the refractive index of the molecular on the media surface, SPR has been widely applied to monitor the molecular binding events on the surface of media $[13,14]$ and gradually became a popular technology in biological detection [15], food safety [16], the medical field [17], and other areas [18]. Compared with the traditional methods of biomedical detections, such as Enzyme-linked immunosorbent assay (ELISA), polymerase chain reaction (PCR), and fluorescence probe-based detection, etc. [19-21], SPR has the advantages of being label-free, having a high sensitivity, and real-time dynamic monitoring [22-24]. According to different excitation ways, the optical coupling mechanisms of SPR biosensing can be further classified into three categories, namely, prism-based coupling, plasmonic waveguide, and metasurfaces coupling [25-27]. The prism coupling 
detection is greatly dependent on the special apparatus, which consists of an intricate optical and a microfluidic system. Hence, the special detection apparatus used in this method enhances the cost and leads to a large volume, for which the application is hard to be used prevalently. Based on the principle of SPP wave, plasmonic waveguides, especially metal-insulator-metal (MIM) waveguides, which consist of a dielectric core and two metal cladding layers have drawn more attention. Due to the strong localization of SPP modes, they can provide acceptable propagation lengths and ease of manufacture over a very wide wavelength range [28-32].

Plasmonic metasurfaces (nano pillars, bowties, capertures/engravings, nanoholes, etc. $[33,34])$ are commonly produced by nanofabrication technology, which can be divided into two basic methods bottom-up and top-down methods, according to their different manufacture crafts. Briefly, the former is based on the conditions of a chemical reaction to change the size and shape of the nanomaterials. The latter usually relies on the nanoimprinting and lithography technologies, such as thermal nanoimprinting, ultraviolet nanoimprinting, electron beam lithography (EBL), focused ion beam (FIB) lithography, deep silicon etching, etc. [35]. The plasmonic metasurface is generally fabricated by the novel metals, which have the characteristics of chemical inertness and bio-functional feasibility. Based on the effects of near-field enhancement, it can be used for both labeled and label-free biosensing. For labeled biosensing, plasmonic surface-enhanced detection techniques can be used to improve the optical output of fluorescent measurements [36-38]. On the contrary, label-free plasmonic biosensing has attracted more attention, which is feasible on the development of environmentally-friendly portable instruments and demonstrates the potential for pointof-care testing. Compared with the biosensing performance of the important dielectric metasurface counterpart $[39,40]$, plasmonic metasurface has a lower quality (Q) factor of resonance, but their biomolecule sensitivity is usually much higher. This is attributed to the greater near-field concentration and confinement, which is typically within the size scope various biomolecules [10]. The metasurface-based coupling on the specific metal nanostructure is easily detectable by a flexible and tiny device. Besides this, it also has several notable merits compared to prism coupling: wider detection range, better sensing linearity, and more diverse customization. As a result, biomolecular sensors based on metasurfaces are projected to have a greater potential in the clinical diagnosis of a variety of diseases, including malignancies and pandemics.

Cancer is one of the most crucial factors that affecting human life. Noninvasive imaging, endoscopic, and ELISA are usually used in cancer detection [41-48]. However, all of these approaches suffer from several certain limitations involving low sensitivity, inconvenience, and risk of perniciousness, which limit its applicability in the prediagnosis and prognosis of cancer. In the process of cancer detection, tumor markers play an important role. According to the different biological structures, the markers can be divided into protein markers and non-protein markers [49-55]. To detail the specific application of metasurfaces on the tumor prediagnosis, the protein markers including Carcinoembryonic Antigen sensing (CEA), Prostate-specific antigen (PSA), and other protein tumor indicators, combing with the non-protein markers as exosomes, are illustrated in this review. Compared with traditional detection techniques, the advantages of metasurfaces-based detection in early screening and detection are highlighted.

Additionally, the potential application of metasurfaces sensing in the current pandemic of COVID-19 is also introduced. Up to date, the conventional detection methods involving ELISA and PCR are major techniques to diagnose the infection. However, the complicated operation and long detective period are still major challenges for these methods, especially when the sample number are huge. To improve the screening efficiency of the COVID-19 pandemic and enhance the responsiveness for other pandemics in the future, better and faster diagnostic technologies are urgently needed. The metasurface-based biosensing we have mentioned above is regarded as an interesting alternative approach, where the feasibility in infectious detection has been widely demonstrated in many studies. Thereby, this technology is a promising technique for the rapid diagnosis of viruses. 
To investigate the potential applications of metasurfaces sensing in detail, four sections have been illustrated in this review. In Section 1, we illuminate the physical basics of plasmonic biosensing and demonstrate various typical applications of plasmonic metasurfaces on cancer and COVID-19 detection; the specific applications are summarized in Figure 1. In Section 2, we discuss the principles of metasurfaces which are based on the SPR, LSPR, and hybrid modes. In Section 3, we mainly focus on the application of plasmonic metasurfaces sensors in cancer detection. In Section 4, we introduce the application of continuous periodic metasurfaces and discrete self-assembled metasurfaces in COVID-19 detection. Finally, we discuss how plasmonic surface sensors could be used to detect cancer and viruses.

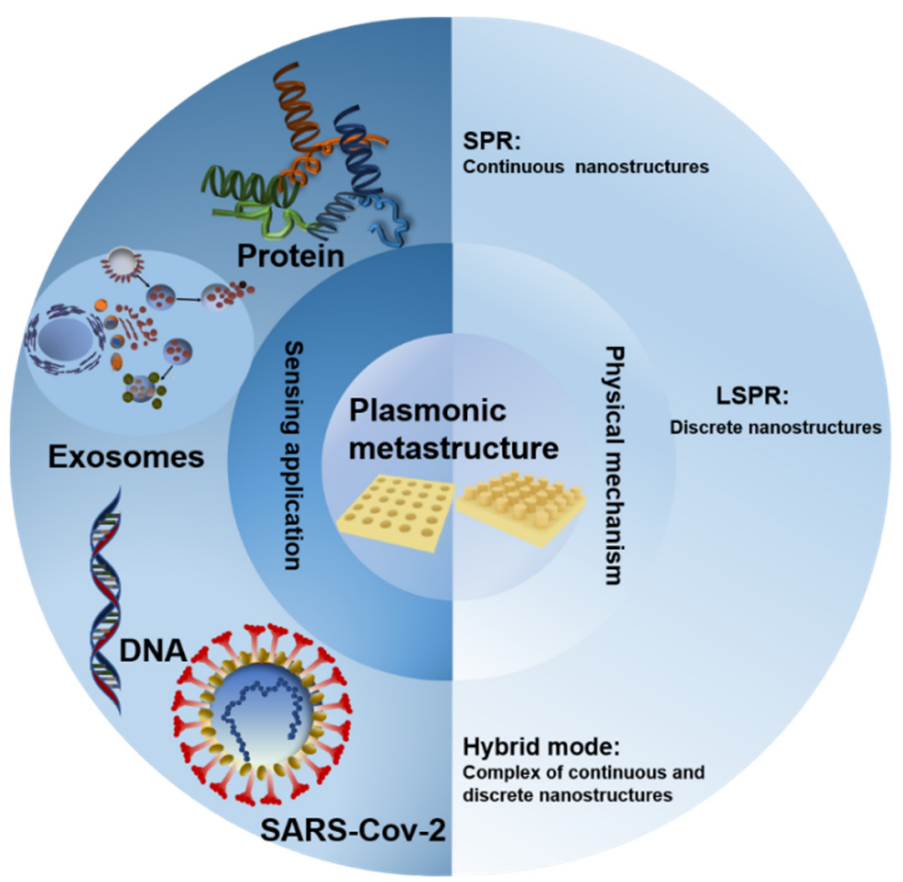

Figure 1. An overview of this review, the center is the typical sensing structure of plasmonic metasurfaces.

\section{Principles of Metasurfaces Biosensing}

The light-matter interaction through the evanescent field of SPR is a common mechanism for biomedical analytes detection [56]. The metasurface sensors based on SPR and LSPR are mainly based on the analysis of angle, wavelength, phase, and other plasmon parameters [57-62]. Metasurfaces-based SPR refers to a kind of artificial meta-atoms (usually periodic) that are designed to manipulate the amplitude, phase, and polarization of electromagnetic waves [63-68]. Compared with the traditional prism coupling-based SPR, the detective facility for metasurfaces-based SPR is easier to be fabricated and the signal is also more stable [69-71]. In terms of periodic arrays, the near-field and far-field coupling is utilized to generate resonance with a high quality $Q$ factor on the metasurfaces, and the effect of the collective mode resonance significantly breaks the damping limit of a single metal nanostructure in the dipole approximation. In the case of SPR, it is usually impossible to excite the SPP directly at a perpendicular incidence because the wave vectors do not match directly, whereas, for the periodic array structure (2D grating structure), the diffraction wave will produce a tangential wave vector component provided by the grating of lattice vector, while the waves are incident to the surface of a metal grating. The excitation condition for SPP of periodic grating structure can be written as: [13]

$$
\lambda=\frac{a_{0}}{\sqrt{m^{2}+n^{2}}} \sqrt{\frac{\varepsilon_{m} \varepsilon_{d}}{\varepsilon_{m}+\varepsilon_{d}}} .
$$


where $\varepsilon_{m}$ and $\varepsilon_{d}$ are metal permittivity and dielectric permittivity, respectively; $a_{0}$ is the lattice constant; and $m, n$ are the scattering orders. On the basis of the equation above (Equation (1)), we can easily draw the positive correlations between the refractive index of the environment changes and resonance wavelength, which is the exact physical mechanism of periodic metasurfaces for biosensing.

In addition to the continuous periodic metasurfaces arrays, some self-assembly (a kind of array with random distribution, which still possesses a certain periodic trend in statistics) metastructures, and other hybrid modes also play an important role in the LSPR domain. LSPR can enhance the electromagnetic field to change its absorption, reflection, and transmission properties for detecting biomolecules [72]. The resonance effect of LSPR can be regarded as a metal spherical nanoparticle with a radius of $a(a \ll \lambda)$ under the action of an electromagnetic field. By solving the Laplace equation with a boundary condition, combing with metal Drude mode formula, then ignoring the damping effect, the resonance frequency $w_{l}$ of LSPR can be defined as [73]:

$$
w_{l}=w_{P}\left[\frac{l}{\varepsilon_{d}(l+1)+l}\right]^{\frac{1}{2}}
$$

where $\varepsilon_{d}$ and $w_{p}$ are the permittivity of environment and plasma frequency, respectively, and $l$ is the angular momentum of the resonant mode. This is similar to the sensing mechanism of the SPR. The variation of background permittivity $\varepsilon_{d}$ will lead to the spectral shift $\Delta w$ (correspondingly $\Delta_{\lambda}$ for wavelength) of LSPR, which is the basic sensing mechanism.

For either SPR or LSPR, bulk refractive index sensitivity $(S)$, the figure of merit $(F O M)$, and limit of detection $(L O D)$ are very important elements to metasurface-based sensor performance. $S$ is an important parameter determined by the environmental refractive index changes, derived from the molecular interaction on the surface of metastructures. Thus, it is used to evaluate the sensing capability of an optical sensor. The correspondence between $S$ and $n$ can be described according to Equation (3): [68]

$$
s=\frac{d A}{d n}
$$

where $A$ denotes the measured physical parameters (wavelength, angle, or spectral intensity), and $n$ is the refractive index. Deuterium lamps, halogen lamps, or their combined light sources, paired with optical fibers and spectrometers, are commonly utilized for plasmonic sensors. Changes in the wavelength, angle, and intensity of the spectrum are usually caused by changes in the refractive index $\mathrm{n}$ of the analyte. The sensitivity of plasmon sensors can range from $50 \mathrm{~nm} /$ RIU (refractive index unit) to 30,000 nm/RIU (refractive index unit) depending on structural design and material selection [74].

FOM is another important parameter that is utilized to define the sensor's ability to respond to changes of small refractive index. For plasmonic plane metal structures, FOM is usually not high due to intrinsic losses, but for the metastructures, the intrinsic losses can be reduced by using different materials and structures. The relationship between FOM and $S$ can be defined as [75]:

$$
F O M=\frac{S}{F W H M}
$$

where FWHM represents the full width at half maximum of resonance spectra.

$L O D$ is the third sensing parameter, which is mainly determined by sensitivity and noise level. The relationship between $L O D$ and $S$ can be written as $[73,75]$ :

$$
L O D=m \frac{\sigma_{\text {blank }}}{S}
$$

where $m$ is a numerical factor, and $\sigma_{\text {blank }}$ is the standard deviation of the blank measures. The $L O D$ is mainly determined by sensitivity and noise level, so it can be improved with low noise detectors and light sources. 


\section{Tumor Marker Screening Based on Plasmonic Metasurfaces}

The biosensor based on the SPR is an emerging platform for disease biomarkers detection. Comparing with the ELISA etc., the approach can provide a non-invasive, real-time, label-free, and rapid detection of cancer markers. To gain a precise screening, the selection of suitable cancer biomarkers is very important. According to the general classification of the biological properties of biomarkers, this section focuses on the detailed screening and detection of protein biomarkers, which are widely used in clinical practice, involving CEA sensing, PSA, and exosomes (Figure 2).

(a)

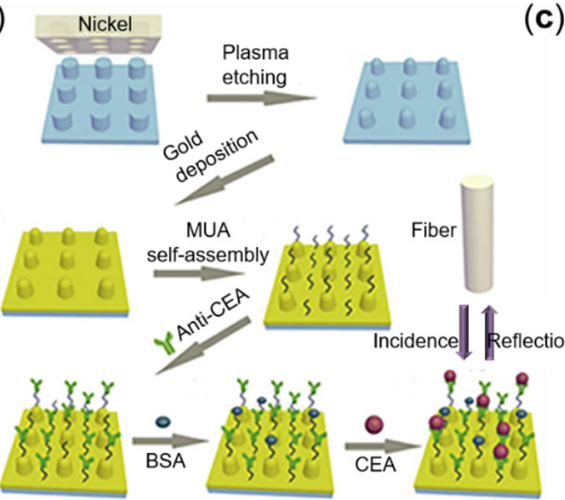

(b)

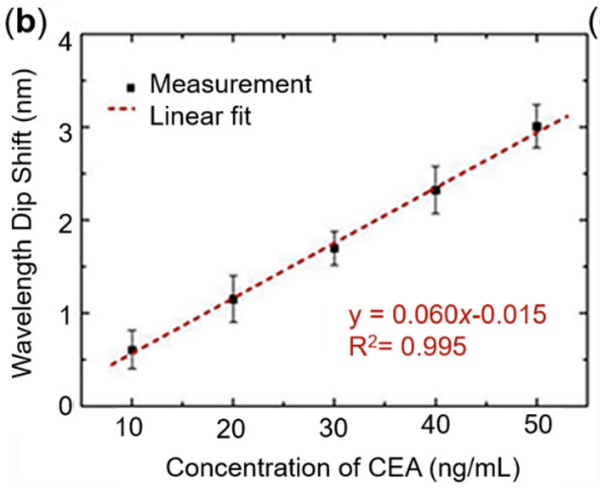

(c)

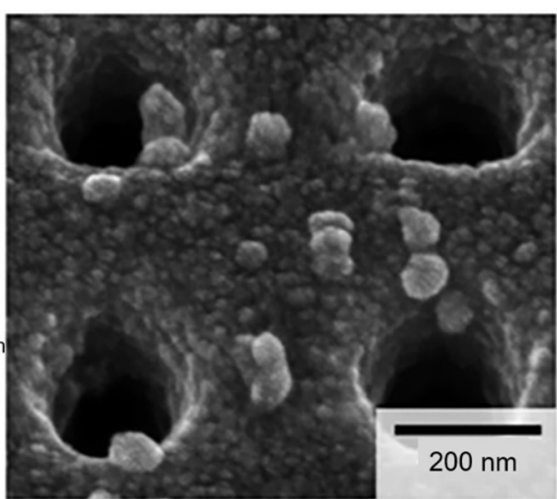

(d)

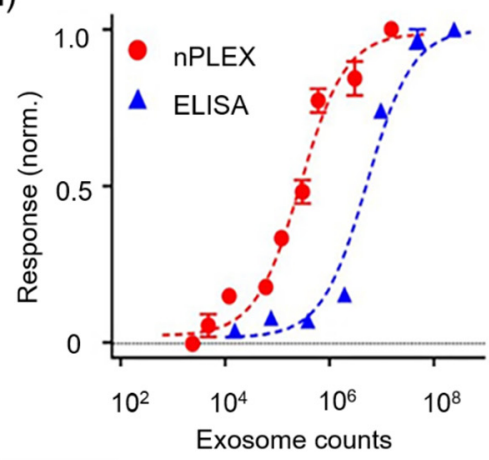

Figure 2. Functionalization of different nanostructures and sensing performance. (a) Biofunctionalization of periodic nanorods. (b) The linear fitting relationship between wavelength dip shift migration and CEA concentration. (c) Scanning electron microscope (SEM) image of exosomes captured by functionalized nanohole arrays. (d) Comparison of exosome detection sensitivity between nanohole chip and ELISA. Reprinted $(\mathbf{a}, \mathbf{b})$ with permission from Reference [76]. Reprinted (c,d) with permission from Reference [77].

\subsection{CEA Sensing}

CEA is a cell membrane glycoprotein expressed by normal mucocytes. The normal content of CEA in adults' bloodstream is approximate $2.5 \mathrm{ng} / \mathrm{mL}$, while the content in tumor patients usually surges to $100 \mathrm{ng} / \mathrm{mL}$ or more. The elevation of CEA in serum commonly indicates the possibility of colorectal cancer, gastric cancer, breast cancer, lung cancer, and ovarian cancer [78]. Therefore, as a conventional broad-spectrum tumor marker, CEA detection has been widely studied in the SPR field. Zhu et al. have produced a cyclical hard gold nanohole array by using nanoimprint and oxygen plasma etching technology [79]. Combining with the soft nano-imprinting lithography, microfluidics, antibody functionalization, and mobile optical spectroscopy, they established a cost-effective plasmonic metasurfaces immune sensing platform, which realized the portable detection of CEA. By plotting the changes of wavelength dip on the event of CEA binding, the shift of wavelength dip against different CEA concentrations will decrease or increase linearly in a special range. The real CEA content in the serum of cancer patients was utilized to assess the detection, and the result demonstrated a high accuracy with a very small error, referring to 
the real content. The sensitivity is up to $490.2 \mathrm{~nm} / \mathrm{RIU}$, and the limit of detection (LOD) was $5 \mathrm{ng} / \mathrm{mL}$, four times lower than the threshold of $20 \mathrm{ng} / \mathrm{mL}$ of CEA detection. Based on the gold nanohole array in the visible light regime, they achieved stability and high-sensitivity detection by using the microfluidic technology, then provided a new solution for portable medical and real-time diagnosis [79]. The manufacturing process of the hard substrate is complex, which is inconvenient to the application of the smart devices. To simplify the process, Zhu et al. further designed a flexible periodical nanopillar. By coating the gold film with the polycarbonate substrate IPS (Polycarbonate), the sensitivity and LOD of the bio-functional IPS were boosted to $454.4 \mathrm{~nm} / \mathrm{RIU}$ and $5 \mathrm{ng} / \mathrm{mL}$, respectively; illustrations are shown in Figure 2a,b. In addition, the manufacturing steps and cost are also reduced. This technology is suitable for large-scale production and commercialization and shows the potential for clinical and future applications in flexible wearable devices [76].

\subsection{PSA Sensing}

PSA is a glycoprotein mainly secreted by the prostate cells. However, it is also a tumor marker, usually utilized for carcinoma diagnosis. The diagnostic gray of PSA is $4.0-10 \mathrm{ng} / \mathrm{mL}$, and when the concentration is higher than $10 \mathrm{ng} / \mathrm{mL}$ in serum, the risk of prostate cancer is increased [80]. Therefore, the accurate quantization of PSA levels is very important for the early diagnosis of cancer $[81,82]$. Khan et al. provided an idea for monitoring other biological interactions by virtue of DNA aptamers. Due to the advantages of strong versatility, resistance to degeneration, and substrate recovery [83], the DNA aptamer-functionalized gold nanodisk array achieved a bulk sensitivity of $113 \mathrm{~nm} / \mathrm{RIU}$ based on LSPR extinction spectroscopy, and the $L O D$ is as low as $1.49 \mathrm{ng} / \mathrm{mL}$ with the dynamic range from 1.7 to $20.4 \mathrm{ng} / \mathrm{mL}$ in PSA detection [83] as shown in Figure 3a,b. For realizing miniaturization and integration, Lin et al. utilized a kind of reusable gold nanodisk arrays as a nanoprobe at the fiber end used by the Electron Beam Lithography (EBL) and metal peel technology, achieving $100 \mathrm{FG} / \mathrm{mL}$ (3 fM) LOD for the free F-PSA [84]; Couture et al. designed a periodic hexagonal nanohole array through lithography technology on a 4-inch glass wafer. In comparison to single channel measurements with nanohole arrays fabricated with nanosphere lithography, the nanohole array sensors greatly enhanced the signal-to-noise ratio of the plasmonic signal and precision of the measurements with the multiwell plate system for achieving a low antibody detection range. Due to the small molecular weight $(28 \mathrm{kDa})$ [85], PSA usually requires a secondary antibody for the amplification of the plasmonic signal. By using sandwich determination, the $L O D$ of the proposed sensor was lowered to $0.1 \mathrm{nM}$ [86]. 
(a)

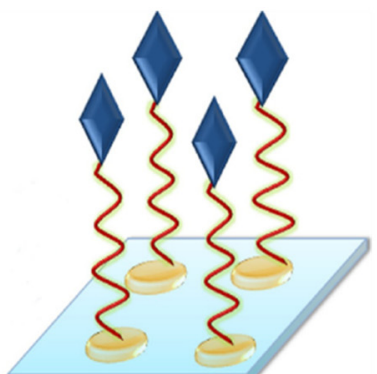

(b)

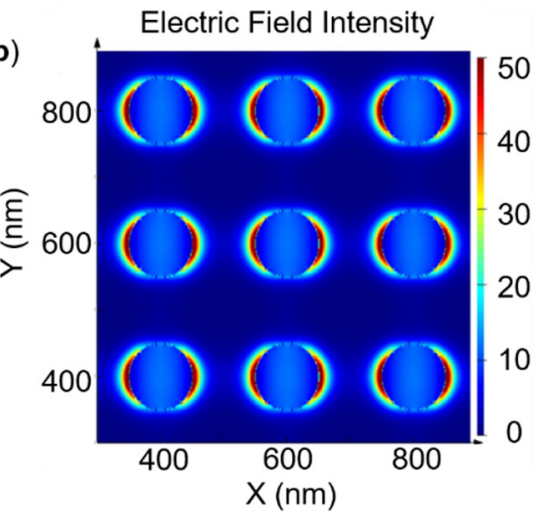

(c)

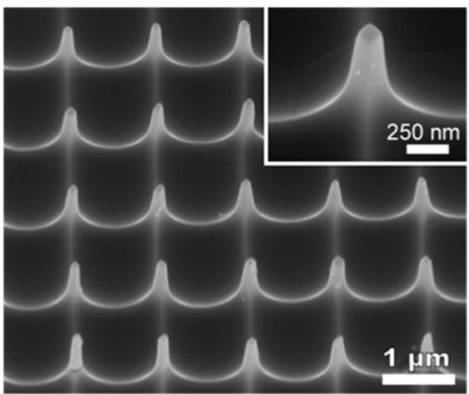

(d)

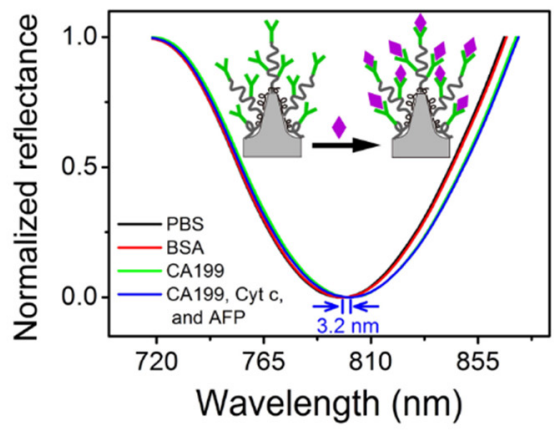

Figure 3. Different nanostructures and PSA sensing performance. (a) Biorecognition process of PSA based on gold nano disks. (b) The distribution of the electric field intensity at resonance around gold nanodisk array by FDTD simulation. (c) Scanning electron microscope (SEM) image (side view) of aluminum nanopyramid array. (d) Reflectance spectra for detecting CA199 based on the anti-CA199 modified Al nanopyramid array by specific interaction in different solutions; Reprinted $(\mathbf{a}, \mathbf{b})$ with permission from Reference [83]. Reprinted (c,d) with permission from Reference [87].

\subsection{Other Protein Tumor Markers Sensing}

Despite of the CEA and PSA, other tumor markers including Tumor necrosis factoralpha (TNF- $\alpha$ ), carbohydrate antigen (CA199), and alpha-fetoprotein (AFP) were studied by the biosensing performed on either different material or shaped metasurfaces. For example, Jin et al. designed a gold nanometer mushroom array. Based on the interaction between the Wood anomaly and local surface plasmon, the refractive index sensor with quality factor is up to $10^{8}$, which approaches the upper limit of the theoretical prediction of a standard PSPR sensor. The array achieves the bulk sensitivity of $1015 \mathrm{~nm} / \mathrm{RIU}$ and was also validated by alpha-fetoprotein detection. Furthermore, the observed $L O D$ reaches $15 \mathrm{ng} / \mathrm{mL}$ [88].

TNF- $\alpha$ is an inflammation-related protein, which plays an important role in disease diagnosis and prediction. Monteiro et al. used a gold nanohole array by transmitted light intensity monitoring to achieve a sensitivity of 4000-5300 IU/RIU and a LOD of $17 \mathrm{pg} / \mathrm{mL}$ [89]. Aluminum has an advantage over the classic noble metal induction process because of its natural abundances, low cost, ease of processing and large-scale manufacturing, and ease of processing with a range of technologies, including complementary metal oxide semiconductor process. However, aluminum's plasmonic mode is limited by its UVgreen wavelength, poor refractive index, facile surface oxidation, and structure dependence, which hinder the application of aluminum in plasmonic biosensing. Zhou et al. achieved a rapid detection of tumor marker CA199 via a uniform quasi-three-dimensional aluminum nanocone array, which could generate the tunable UV-visible-near-infrared plasmons by changing the incident angle and achieving a $L O D$ of $29 \mathrm{ng} / \mathrm{mL}$ in the air [87]. More interestingly, In the immunodetection of the bovine serum protein (BSA) protein antibody, Zhu et al. synthesized nanoimprint printing, oxygen plasma etching, metal film deposition, oxygen plasma passivation, and other processes to prepare 2-inch aluminum nanocrystals on a flexible polymer substrate with a detection limit of $1 \mathrm{pg} / \mathrm{mL}$. The sensitivity of aluminum- 
based metasurfaces is two orders of magnitude higher than that of gold metasurfaces with the same structure, demonstrating improved biomolecular immunodetection ability and clinical application potential [90]. Differing from the conventional detection in the visible band, the THz metamaterial has a precise and tunable vibration frequency, which is consistent with the vibration frequency of some important tumor marker molecules, but its water absorption phenomenon is a major obstacle that hinders the micro-detection of tumor marker antigen antibodies. Geng et al. and co-workers suggested overcoming the issue of water absorption and gained a $14.2 \mathrm{GHz}$ resonance displacement $(0.02524 \mathrm{ug} / \mathrm{mL})$ in tumor marker AFP detection by using a metal nano-cracked ring resonator and Polydimethylsiloxane (PDMS) microchannel [91]. Furthermore, by refining the metamaterial's structure and lowering the matrix's dielectric constant, the sensitivity of specific cancer biomarkers can be boosted even more. This method has strong application potential for the special recognition of early cancer molecules.

\subsection{Tumor-Derived Exosome Sensing}

Exosomes are a kind of extracellular microvesicle secreted by miscellaneous cells in whole human organism and widely exist in blood, urine, saliva, and even breast milk [92]. Due to its ability to transport the molecular contents from the originated cells to the targeted cell, exosome is also notorious for the role of an accomplice in tumor progress. The abnormal increase of exosomes is always found in those patients who suffer from a malignant tumor. Thereby, exosomes are regarded as a potential biomarker in cancer diagnosis. In the absence of biopsy, the capture of exosomes containing molecular information from their parent tumor cells can be used as a novel means to predict and diagnose cancer [93]. However, traditional methods of exosome detection based on ultracentrifugation, western blotting, and ELISA require complicated sample handling and professional experiment operation [94], which limit the detection to realize miniaturization and portability. Recently, the modulated metasurfaces-based detection provides a new idea for fast and portable detection of exosomes. Lee et al. proposed a nanoplasmonic exosomal sensing (nPLEX) technique based on periodic nanohole arrays; the illustration is shown in Figure 2c,d. The nanohole structures greatly improve the detection sensitivity on exosomes by limiting the surface electromagnetic field and enhancing the evanescent field referring to the exosome size ranges $[77,95,96]$. By employing a complementary metal-oxide-semiconductor (CMOS) apparatus, the binding of exosomes to the nanohole surface could be easily reflected by the phase difference or intensity variation, which is induced by the shift of the plasmon resonance signal. The nPLEX array with 36 sensing units can synchronously support 12 potential exosome markers detection in parallel, achieving the LOD of approximately 3000 exosomes $(670 \mathrm{aM})$ in $30 \mathrm{~min}$. Furthermore, the nPLEX platform can be enhanced further by the secondary labeling of Au nanoparticles. The nPLEX chip can be scaled up to improve throughput in clinical applications for high-throughput clinical diagnosis of pancreatic malignancy by multi-marker extracellular vesicle, EV $[95,96]$.

Based on nanohole arrays, Shao et al. measured different populations of circulating amyloid $\beta(A \beta)$ proteins - exosome-bound vs. unbound-directly from blood. The local optical deposits and double-layer plasma nanostructures for in-situ enzyme conversion were used to achieve high sensitivity. More interestingly, the multi-channel population analysis achieves high sensitivity (about 200 exosomes) and can attain the co-localization of multiple targets in exosomes. This shows the important role of exosomes in the diagnosis of Alzheimer's [97]. Illustrations are shown in Figure 4a-c. Liu et al. designed an integrated microfluidic device of nanoporous gold $(\mathrm{Au})$ with modified membrane nanoclusters to capture antibodies. The second antibody-coupled gold nanorod probe was loaded under a dark field microscope to identify and quantify the specificity of lung cancer. Exosomes can be used to isolate and detect on-site lung cancer-specific exosomes collected from the patient's urine. Due to resonance Rayleigh scattering, the complex produces a significant scattering wavelength shift and increases the scattering intensity, which enables the ultra- 
sensitive detection of exosomes with a LOD less than 1000 particles/mL [98], as shown in Figure $4 d$,e.

(a)

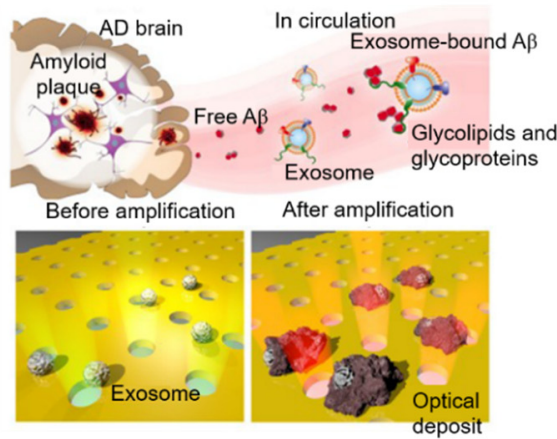

(b)

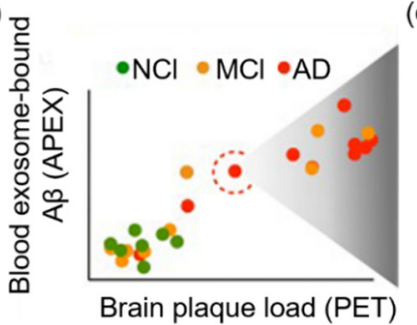

(c)

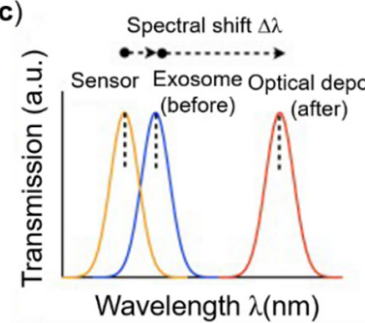

(d)

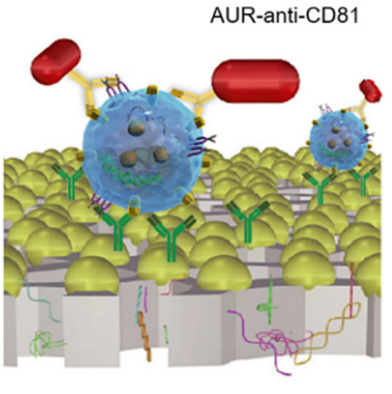

AUNC-Exosome-AuR

(e)

Figure 4. Performance of different nanostructures and sensing performance for exosomes. (a) Exosomes associate with $\mathrm{A} \beta$ proteins. The $\mathrm{A} \beta$ protein, the main component of amyloid plaques found in $\mathrm{AD}$ brain pathology, is released into the extracellular space. Exosomes are nano-scale outer cell membrane vesicles secreted by mammalian cells. Exosomes bind to the released A $\beta$ protein through their surface glycoproteins and glycolipids (b) The APEX platform was used to measure exosomalbound $A \beta$ in blood samples of Alzheimer's disease (AD), mild cognitive impairment (MCI), and no cognitive impairment (NCI) control groups. The blood measurement results are correlated with the corresponding PET imaging of cerebral amyloid plaque deposition. (c) A representative schematic diagram of the change transmission spectrum with APEX magnification. The APEX platform monitors the specific exosome binding (before) and the subsequent amplification spectrum (after) transmission spectrum shift $(\Delta \lambda)$. a.u arbitrary unit. (d) Schematic illustration of in-situ detection of exosome (e) Correlation of AuNC-Exosome-AuR signal ratio against to exosome concentration. Reprinted $(\mathbf{a}, \mathbf{c})$ with permission from Reference [97]. Reprinted (d,e) with permission from Reference [98].

In addition to the conventional two-dimensional nanohole arrays, Pang et al. studied and compared two-dimensional nanoholes, quasi-three-dimensional nanohole arrays, and 3D photonic crystal structures. Due to the hybrid coupling of LSPR and Fabry-Perot cavity modes, the quasi-three-dimensional hole structure was stronger. The electromagnetic field is relative to the two-dimensional nanopore. In the comparison of these three structures, it is found that the 3D photonic crystal structure based on plasmonics and photonic crystal modes has a higher sensitivity, reaching $1376 \mathrm{~nm}$ RIU-1. Peak shift increased to $102 \mathrm{~nm}$ as exosome concentration increased to $1 \times 10^{11}$ particles per $\mathrm{mL}$. It shows the potential of 3D photonic crystal structure in the process of exosome detection [99]. Performances of various nanostructured arrays for cancer detection are summarized in Table 1. 
Table 1. Performances of tumor markers based on metasurfaces.

\begin{tabular}{ccccc}
\hline Metastructure & Analytes & Bulk Sensitivity & LOD & Reference \\
\hline Nanohole & CEA & $490.2 \mathrm{~nm} / \mathrm{RIU}$ & $5 \mathrm{ng} / \mathrm{mL}$ & {$[79]$} \\
Nanopillar & CEA & $454.4 \mathrm{~nm} / \mathrm{RIU}$ & $5 \mathrm{ng} / \mathrm{mL}$ & {$[76]$} \\
Nanocup & CEA & $800 \Delta \mathrm{T} \% / \mathrm{RIU}$ & $10 \mathrm{ng} / \mathrm{mL}$ & {$[100]$} \\
Nanodisk & PSA & $113 \mathrm{~nm} / \mathrm{RIU}$ & $1.49 \mathrm{ng} / \mathrm{mL}$ & {$[83]$} \\
Nonohole & PSA & $/$ & $0.1 \mathrm{nM}$ & {$[86]$} \\
Nanohole & CD24 & $/$ & $0.18 \mathrm{ng} / \mu \mathrm{L}$ & {$[77]$} \\
Nanopyramid & CA199 & $819 \mathrm{~nm} / \mathrm{RIU}$ & $29 \mathrm{ng} / \mathrm{mL}$ & {$[87]$} \\
Nanomushroom & AFP & $1015 \mathrm{~nm} / \mathrm{RIU}$ & $15 \mathrm{ng} / \mathrm{mL}$ & {$[88]$} \\
Nanosplit-ring & AFP & $/$ & $0.02524 \mu \mathrm{m} / \mathrm{mL}$ & {$[91]$} \\
Nanohole & TNF- $\alpha$ & $4000-5300 \mathrm{IU} / \mathrm{RIU}$ & $17 \mathrm{pg} / \mathrm{mL}$ & {$[89]$} \\
Nanohole & A $\beta$ & $/$ & $200 \mathrm{exosomes}$ & {$[97]$} \\
Nanoporosity & CD-63 & $/$ & $1 \mathrm{particle} / \mu \mathrm{L}$ & {$[98]$} \\
Nanohole & Exosomes & $1736 \mathrm{~nm} / \mathrm{RIU}$ & & $/$ \\
Nanopillar & CEA & $/$ & $5 \mathrm{ng} / \mathrm{mL}$ & {$[99]$} \\
Nanodisk & PSA & $/$ & $1.6 \mathrm{ng} / \mathrm{mL}$ & {$[40]$} \\
\hline
\end{tabular}

\section{COVID-19 Sensing Based on Plasmonic Metastructures}

Since the beginning of the COVID-19 pandemic, infectious disease has brought a huge health threat to the whole world [102]. The rapid screening and insulation of the infectious person from the healthy population is still a major means of pandemic control. Many reviews have introduced the development of COVID-19 and its detection methods [103-119]. Nucleic acid amplification and serological testing are two common methods of COVID-19 detection [120-125]. Nucleic acid detection based on two steps of operations consists of reverse transcription-polymerase chain reaction (RT-PCR) and real-time fluorescence quantify PCR (Q-PCR) is still a gold standard for the infection screening [126-129]. However, this method has the disadvantages of long period detection time, is expensive, and requires professional operation [115]. Serological test including ELISA and later flow assay (LFA) is another common detection method of pathogen infection, which can rapidly identify an infectious individual who has the immune response [130-136]. Similar to nucleic acid detection, either ELISA or LFA also suffer numerous complicated operations, including antibody coating, blotting, longtime incubation, scrubbing, and chemical reaction, which limit its application to POC [134]. Due to the unavoidable disadvantages that exist in nucleic acid detection and serological tests, a rapid detection method with real-time, unlabeled, and miniaturization is urgently needed [137-139]. The metasurfaces-based SPR detection is expected to be an alternative but more promising approach, which could achieve a real-time, unlabeled, and rapid detection on COVID-19.

\subsection{Detection Based on Metasurfaces}

Recently, some researchers have developed diversified detection of SARS-CoV-2 based on SPR technology $[140,141]$, as shown in Figure 5a-d. Liu et al. used gold discrete nanocup arrays to detect the novel coronavirus spike protein and gained a $L O D$ of $370 \mathrm{vp} / \mathrm{mL}$ with a decent detective range from 0 to $10^{7}$ based on a label-free LSPR biosensor with an extraordinary optical transmission (EOT) effect. Results are illustrated in Figure 5a,b. In addition, gold nanoparticles are used to enhance the sensitivity of the sensor, quantify the low concentration analysis in a solution with limited diffusion conditions, and amplify the optical signal to shorten the detection time. Similar fast and sensitive detection capabilities were demonstrated using low-cost handheld optical devices controlled by a smartphone application (APP) program. The LOD of SARS-CoV-2 pseudo viruses in hand-held systems was about 4000 virus particles within 15 min [140]. Yanik et al. developed a kind of plasmonic nanohole arrays, in which the antibody of the spike protein of SARS-CoV-2 was initially immobilized on the surface. By capturing the spike protein, the whole viruses were suspended into the nanohole arrays of grating, and directly resulted in the oscillator redshift of the resonant frequency, when the grating coupling of the incident light on the 
surface. On the basis of this, small (vesicular stomatitis virus and pseudo Ebola-virus) and large (vaccinia virus) enveloped viruses can be non-destructively detected [142].
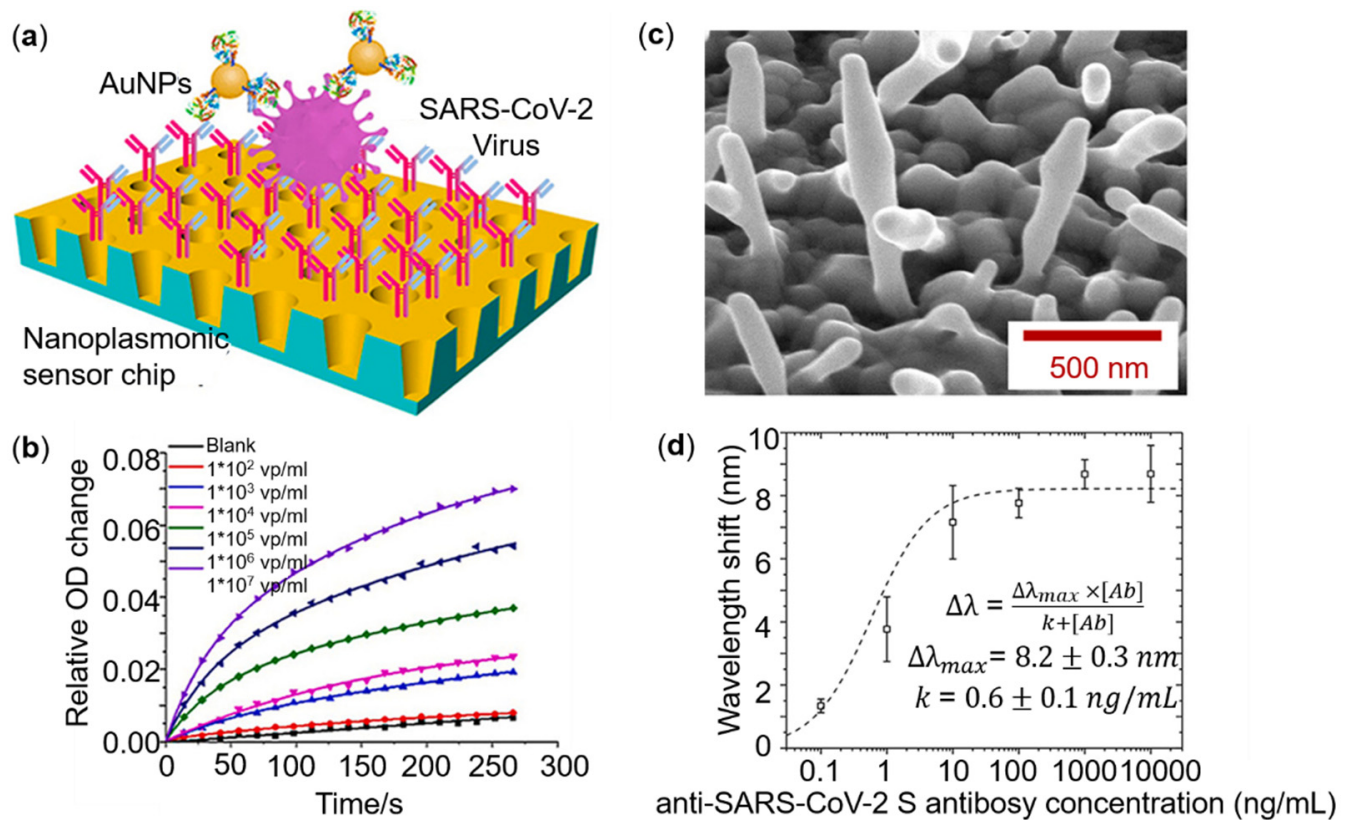

Figure 5. Different structures and sensing properties of SARS-CoV-2 detection. (a) Schematic diagram of nanocup array for COVID-19 detection. (b) SARS-CoV-2 mAbs labeled AuNP enhanced binding curves with different concentrations of the SARS-CoV-2 pseudo virus over the range $0-1.0 \times 10^{7} \mathrm{vp} / \mathrm{mL}$. (c) SEM diagram of nano spikes structure. (d) LSPR responses at different anti-SARS-CoV-2 spike protein antibody concentrations. Reprinted $(\mathbf{a}, \mathbf{b})$ with permission from Reference [140]. Reprinted (c,d) with permission from Reference [141].

\subsection{Detection Based on Self-Assembled Metastructures}

Self-assembled metastructures are another nascent metasurfaces, which are also able to be used for virus detection. Funari et al. manufactured gold nanospikes metasurfaces based on electrodeposition technology combined with optical probes to form an optical microfluidic sensing platform. Based on the changes in the local environmental refractive index caused by the interaction between the SARS-COV-2 spike protein and the antibody in the diluted human serum, the shift of the LSPR resonance peak was detected, and a detection concentration of $0.08 \mathrm{ng} / \mathrm{mL}$ was achieved. The diagnostic platform demonstrates the potential to complement existing serological assays and improve COVID-19 diagnosis; the results are shown in Figure 5c,d [141]. Furthermore, a significantly higher sensitivity (picomolar) was achieved by Qiu et al. By combining the hybrid effect of plasma photothermal and LSPR, they enhanced the LOD of virus sequences to $0.22 \mathrm{pM}$, providing a new idea for the detection of COVID-19 [143,144]. On the other hand, the self-assembling nanoparticles made by noble metal are also used to amplify optical signals in the biosensing process. Das et al. gained a LOD of the spike of SARS-COV-2 to $111.11 \mathrm{deg} / \mathrm{RIU}$ by using a gold nanorod nanoparticle with a Kretschmann prism configuration [145]; Parikshit et al. proposed the LSPR colorimetric sensor composed of gold nanoparticles. The assay is based on the specific targeting and binding ability of antisense oligonucleotides to the $\mathrm{N}$ gene of the SARS-CoV-2 virus genome. By immobilizing the antisense oligonucleotides to gold nanoparticles, the SPR signal derived from binding events was significantly enhanced. In the presence of SARS-CoV-2 target RNA sequence, the AuNP at the closure of ASOs (antisense oligonucleotides) modified by mercaptan was selectively aggregated, which induces a redshift of about $40 \mathrm{~nm}$ in its absorption of SPP spectrum. Based on this method, positive cases infected by SARS-CoV-2 were diagnosed within 10 min [146]. Ahmadivand et al. designed a ring plasma cell sensor to detect the $S$ protein. The assay illustrates an excellent 
sensitivity with an extreme LOD of $4.2 \mathrm{fM}$ by antibody-AuNP complex. It is also worth mentioning that the transmission spectrum of the meta-sensor enables the movement of a polarized beam that excites the etheric Hertz frequency, which confers a promising application in the point of care (POC) filed [147]. Cheong et al. developed a compact nano PCR system that enables SARS-CoV-2 RNA to be detected by a portable device. Rapid thermal cycling (via plasma heating of magneto-plasma nanoparticles) and in situ fluorescence detection was enabled after the magnetic removal of nanoparticles. By using this approach, three samples can be measured simultaneously within $17 \mathrm{~min}$, and the LOD was as low as 3.2 gene/uL [148]. Gao et al. combined three modes of colorimetry, SERS, and fluorescence detection to detect the RNA of the COVID-19 virus, achieving a LOD of $160 \mathrm{fM}$ after $40 \mathrm{~min}$ of incubation [149]. The typical sensing performance of metasurfaces devices for COVID-19 is summarized in Table 2.

Table 2. Performance of COVID-19 based on metasurfaces.

\begin{tabular}{cccc}
\hline Metastructure & Analytes & LOD & Reference \\
\hline Nanospike & S protein & $0.08 \mathrm{ng} / \mathrm{mL}$ & {$[141]$} \\
Nanocup & S protein & $370 \mathrm{vp} / \mathrm{mL}$ & {$[140]$} \\
Nanoisland & SARS-CoV-2 & $0.22 \mathrm{pM}$ & {$[143,144]$} \\
Nanorod & S protein & $111.11 \mathrm{deg} / \mathrm{RIU}$ & {$[145]$} \\
Nanoparticle & N gene & $0.18 \mathrm{ng} / \mathrm{uL}$ & {$[146]$} \\
Toroidal metasurface/nanoparticle & S protein & $4.2 \mathrm{fM}$ & {$[147]$} \\
Nanohole & S protein & $/$ & {$[142]$} \\
Nanoparticle & RNA & $160 \mathrm{fM}$ & {$[149]$} \\
Nanoparticle & RNA & $3.2 \mathrm{gene} / \mathrm{uL}$ & {$[148]$}
\end{tabular}

\section{Conclusions and Future Trend}

In this paper, we briefly review the applications of plasmonic metasurfaces in biosensing. We discuss the physical sensing mechanisms of the metasurface, focusing on recent applications of cancer detection and COVID-19 detection.

As for the future development of plasmonic metasurface sensing, we believe that there is still a great part room for improvement of either detection devices or plasmon materialization and commercialization. At present, plasmonic-based disease detection is limited to serum, which needed a complicated preprocessing in the professional laboratory before detection. However, in order to achieve the POCT, by capturing and manipulating light on the chip, and manipulating discrete chemical samples on micron and sub-micron scale chip structures to enhance the function of the chip chemical platform, it may further promote the development of plasmon miniaturization [150-156] and more accessible sample involving whole blood, or even involving sweat, saliva, and urine may be a better choice. This will also bring a greater challenge to portable medical applications in health diagnoses. With the rapid development of optical technology, in terms of devices with complicated functions, small-scale and high-integration density is expected to be more flexible and wearable [157], and plasmonic biosensing can be used in wearable devices to detect those complicated samples in real-time.

The Biacore series of commercialized plasmonic biosensors (such as the American General Electric Company's Biacore 8K series) are based on flat metal film and uses the SPP effect activated by evanescent waves. It is mainly used to analyze the binding kinetics and affinity tests of biomolecules. The commercialization of plasmon metasurfaces instant detection equipment still needs a certain process. There are no mature instruments in the market. In the future, it may be necessary to solve the problem of large-scale manufacturing of plasmon chips while maintaining cost control and promoting the commercialization process well.

On the other hand, metamaterial is another approach to improving detection efficiency and lowering the commercial cost, so the development of novel materials and structural design will boost detection technology [158-162]. Conventional noble metals are commonly 
used in plasmonic sensing; however, an inherent feature of optical loss is that it is hard to be overcome. TiN is a novel material which has been recently used in plasmonic study due to its stable chemical property and free carrier concentration close to that of gold. The nonlinear optical response based on free carriers provides a wide spectral response range. More intriguingly, TiN has one order of magnitude better stability than gold and other noble metal plasmon materials. Furthermore, TiN is a low cost and easily available material, which confers its promising commercial application in plasmonic biosensing. Apart from the material selection, the structural design of the medium is also an alternative optimization scheme for plasmonic biosensing [163,164]. The required metastructure is reversely developed in conjunction with artificial intelligence to achieve molecular customized sensing during biosensing and make efficient use of the electromagnetic field's improved hot spot [165-168].

Author Contributions: Conceptualization, J.Z.; methodology, Z.W.; data review, Z.W., J.S., Q.D., and X.L.; Manuscript structure and proof reading by S.A.K., Writing-Original draft preparation, Z.W., J.C., F.L., and J.S.; writing-review and editing, J.Z. supervision, J.Z. All authors have read and agreed to the published version of the manuscript.

Funding: This work was supported by NSFC (62175205), NSAF (U1830116, U2130112), the Natural Science Foundation of Fujian Province (2020J06009), the Open Fund of State Key Laboratory of Applied Optics (SKLAO2020001A15), Xiamen Science and Technology Bureau (3502Z20203006), and the Fundamental Research Funds for the Central Universities (Grant No. 20720190010).

Institutional Review Board Statement: Not applicable.

Informed Consent Statement: Not applicable.

Data Availability Statement: Not applicable.

Acknowledgments: Not applicable.

Conflicts of Interest: The authors declare no conflict of interest.

\section{References}

1. Wood, R.W. XLII. On a remarkable case of uneven distribution of light in a diffraction grating spectrum. Philos. Mag. Ser. 1902, 4, 396-402. [CrossRef]

2. Mie, G. Beiträge zur Optik trüber Medien, speziell kolloidaler Metallösungen. Ann. Phys. 1908, 330, 377-445. [CrossRef]

3. Fano, U. The theory of anomalous diffraction gratings and of quasi-stationary waves on metallic surfaces (Sommerfeld's waves). J. Opt. Soc. Am. 1941, 31, 213-222. [CrossRef]

4. Ritchie, R.H. Plasma losses by fast electrons in thin films. Phys. Rev. 1957, 106, 874. [CrossRef]

5. Hessel, A.; Oliner, A. A new theory of Wood's anomalies on optical gratings. Appl. Opt. 1965, 4, 1275-1297. [CrossRef]

6. Fleischmann, M.; Hendra, P.J.; McQuillan, A.J. Raman spectra of pyridine adsorbed at a silver electrode. Chem. Phys. Lett. 1974, 26, 163-166. [CrossRef]

7. Maier, S.A.; Brongersma, M.L.; Kik, P.G.; Meltzer, S.; Requicha, A.A.; Atwater, H.A. Plasmonics-A route to nanoscale optical devices. Adv. Mater. 2001, 13, 1501-1505. [CrossRef]

8. Otto, A. Excitation of nonradiative surface plasma waves in silver by the method of frustrated total reflection. Z. Phys. A Hadron. Nucl. 1968, 216, 398-410. [CrossRef]

9. Kretschmann, E.; Raether, H. Radiative decay of non-radiative surface plasmons excited by light. Z. Naturforsch. A 1968, 23, 2135-2136. [CrossRef]

10. Mayer, K.M.; Hafner, J.H. Localized surface plasmon resonance sensors. Chem. Rev. 2011, 111, 3828-3857. [CrossRef] [PubMed]

11. Liang, Y.; Li, L.; Lu, M.; Yuan, H.; Long, Z.; Peng, W.; Xu, T. Comparative investigation of sensing behaviors between gap andlattice plasmon modes in a metallic nanoring array. Nanoscale 2018, 10, 548-555. [CrossRef]

12. Ebbesen, T.W.; Genet, C.; Bozhevolnyi, S.I. Surface-plasmon circuitry. Phys. Today 2008, 61, 44. [CrossRef]

13. Barnes, W.L.; Dereux, A.; Ebbesen, T.W. Surface plasmon subwavelength optics. Nature 2003, 424, 824-830. [CrossRef] [PubMed]

14. Gramotnev, D.K.; Bozhevolnyi, S.I. Plasmonics beyond the diffraction limit. Nat. Photonics 2010, 4, 83-91. [CrossRef]

15. Mauriz, E.; Dey, P.; Lechuga, L.M. Advances in nanoplasmonic biosensors for clinical applications. Analyst 2019, 144, 7105-7129. [CrossRef] [PubMed]

16. Bülbül, G.; Hayat, A.; Andreescu, S. Portable nanoparticle-based sensors for food safety assessment. Sensors 2015, 15, 30736-30758. [CrossRef] [PubMed] 
17. Hirsch, L.R.; Stafford, R.J.; Bankson, J.; Sershen, S.R.; Rivera, B.; Price, R.; Hazle, J.D.; Halas, N.J.; West, J.L. Nanoshell-mediated near-infrared thermal therapy of tumors under magnetic resonance guidance. Proc. Natl. Acad. Sci. USA 2003, 100, 13549-13554. [CrossRef]

18. Fan, M.; Andrade, G.F.; Brolo, A.G. A review on recent advances in the applications of surface-enhanced Raman scattering in analytical chemistry. Anal. Chim. Acta 2020, 1097, 1-29. [CrossRef]

19. Esfandyarpour, R.; Esfandyarpour, H.; Harris, J.S.; Davis, R.W. Simulation and fabrication of a new novel 3D injectable biosensor for high throughput genomics and proteomics in a lab-on-a-chip device. Nanotechnology 2013, 24, 465301. [CrossRef]

20. Qasim, M.; Lim, D.-J.; Park, H.; Na, D. Nanotechnology for diagnosis and treatment of infectious diseases. J. Nanosci. Nanotechnol. 2014, 14, 7374-7387. [CrossRef] [PubMed]

21. Cella, L.N.; Chen, W.; Myung, N.V.; Mulchandani, A. Single-walled carbon nanotube-based chemiresistive affinity biosensors for small molecules: Ultrasensitive glucose detection. J. Am. Chem. Soc. 2010, 132, 5024-5026. [CrossRef]

22. Huang, S.C.; Wang, X.; Zhao, Q.Q.; Zhu, J.F.; Li, C.W.; He, Y.H.; Hu, S.; Sartin, M.M.; Yan, S.; Ren, B. Probing nanoscale spatial distribution of plasmonically excited hot carriers. Nat. Commun. 2020, 11, 4211. [CrossRef] [PubMed]

23. Dahlin, A.B.; Jonsson, M.P. Performance of Nanoplasmonic Biosensors. In Nanoplasmonic Sensors; Dmitriev, A., Ed.; Springer: New York, NY, USA, 2012; pp. 231-265.

24. Consales, M.; Quero, G.; Spaziani, S.; Principe, M.; Micco, A.; Galdi, V.; Cutolo, A.; Cusano, A. Metasurface-Enhanced Lab-on-Fiber Biosensors. Laser Photonics Rev. 2020, 14, 2000180. [CrossRef]

25. Motogaito, A.; Mito, S.; Miyake, H.; Hiramatsu, K. Detecting high-refractive-index media using surface plasmon sensor with one-dimensional metal diffraction grating. Opt. Photonics J. 2016, 6, 164-170. [CrossRef]

26. Špačková, B.; Wrobel, P.; Bocková, M.; Homola, J. Optical biosensors based on plasmonic nanostructures: A review. Proc. IEEE 2016, 104, 2380-2408. [CrossRef]

27. Gao, M.; Yang, W.; Wang, Z.; Lin, S.; Zhu, J.; Yang, Z. Plasmonic resonance-linewidth shrinkage to boost biosensing. Photonics Res. 2020, 8, 1226-1235. [CrossRef]

28. Udupi, A.; Madhava, S.K. Plasmonic Coupler and Multiplexer/Demultiplexer Based on Nano-Groove-Arrays. Plasmonics 2021, 16, 1685-1692. [CrossRef]

29. Kazanskiy, N.L.; Khonina, S.N.; Butt, M.A.; Kaźmierczak, A.; Piramidowicz, R. A Numerical Investigation of a Plasmonic Sensor Based on a Metal-Insulator-Metal Waveguide for Simultaneous Detection of Biological Analytes and Ambient Temperature. Nanomaterials 2021, 11, 2551. [CrossRef] [PubMed]

30. Chou Chau, Y.-F.; Ming, T.Y.; Chou Chao, C.-T.; Thotagamuge, R.; Kooh, M.R.R.; Huang, H.J.; Lim, C.M.; Chiang, H.-P. Significantly enhanced coupling effect and gap plasmon resonance in a MIM-cavity based sensing structure. Sci. Rep. 2021, 11, 18515. [CrossRef]

31. Butt, M.A.; Kaźmierczak, A.; Kazanskiy, N.L.; Khonina, S.N. Metal-Insulator-Metal Waveguide-Based Racetrack Integrated Circular Cavity for Refractive Index Sensing Application. Electronics 2021, 10, 1419. [CrossRef]

32. Ozbay, E. Plasmonics: Merging photonics and electronics at nanoscale dimensions. Science 2006, 311, 189-193. [CrossRef]

33. Song, E.Y.; Lee, G.Y.; Park, H.; Lee, K.; Kim, J.; Hong, J.; Kim, H.; Lee, B. Compact generation of airy beams with C-aperture metasurface. Adv. Opt. Mater. 2017, 5, 1601028. [CrossRef]

34. Zaman, M.A.; Padhy, P.; Hesselink, L. Solenoidal optical forces from a plasmonic Archimedean spiral. Phys. Rev. A 2019, 100, 013857. [CrossRef]

35. Hong, Y.; Huh, Y.-M.; Yoon, D.S.; Yang, J. Nanobiosensors based on localized surface plasmon resonance for biomarker detection J. Nanomater. 2012, 2012, 759830. [CrossRef]

36. Traverso, A.J.; Huang, J.; Peyronel, T.; Yang, G.; Tiecke, T.G.; Mikkelsen, M.H. Low-loss, centimeter-scale plasmonic metasurface for ultrafast optoelectronics. Optica 2021, 8, 202-207. [CrossRef]

37. Luo, S.; Li, Q.; Yang, Y.; Chen, X.; Wang, W.; Qu, Y.; Qiu, M. Controlling fluorescence emission with split-ring-resonator-based plasmonic metasurfaces. Laser Photonics Rev. 2017, 11, 1600299. [CrossRef]

38. Fore, S.; Yuen, Y.; Hesselink, L.; Huser, T. Pulsed-interleaved excitation FRET measurements on single duplex DNA molecules inside C-shaped nanoapertures. Nano Lett. 2007, 7, 1749-1756. [CrossRef]

39. Kuznetsov, A.I.; Miroshnichenko, A.E.; Brongersma, M.L.; Kivshar, Y.S.; Luk'yanchuk, B. Optically Resonant Dielectric Nanostructures. Science 2016, 354, 6314. [CrossRef] [PubMed]

40. Iwanaga, M. All-Dielectric Metasurface Fluorescence Biosensors for High-Sensitivity Antibody/Antigen Detection. ACS Nano 2020, 14, 17458-17467. [CrossRef] [PubMed]

41. Frangioni, J.V. New technologies for human cancer imaging. J. Clin. Oncol. 2008, 26, 4012. [CrossRef]

42. Lambert, R. Endoscopy in screening for digestive cancer. World J. Gatrointest Endcosc. 2012, 4, 518. [CrossRef]

43. Horigome, H.; Nomura, T.; Saso, K.; Itoh, M.; Joh, T.; Ohara, H. Limitations of imaging diagnosis for small hepatocellular carcinoma: Comparison with histological findings. J. Gastroenterol. Hepatol. 1999, 14, 559-565. [CrossRef]

44. Raiko, I.; Sander, I.; Weber, D.G.; Raulf-Heimsoth, M.; Gillissen, A.; Kollmeier, J.; Scherpereel, A.; Brüning, T.; Johnen, G. Development of an enzyme-linked immunosorbent assay for the detection of human calretinin in plasma and serum of mesothelioma patients. BMC Cancer 2010, 10, 242. [CrossRef]

45. Lind, K.; Kubista, M. Development and evaluation of three real-time immuno-PCR assemblages for quantification of PSA. J. Immunol. Methods. 2005, 304, 107-116. [CrossRef] 
46. Tian, J.; Zhou, L.; Zhao, Y.; Wang, Y.; Peng, Y.; Zhao, S. Multiplexed detection of tumor markers with multicolor quantum dots based on fluorescence polarization immunoassay. Talanta 2012, 92, 72-77. [CrossRef] [PubMed]

47. Pujol, J.-L.; Grenier, J.; Daurès, J.-P.; Daver, A.; Pujol, H.; Michel, F.-B. Serum fragment of cytokeratin subunit 19 measured by CYFRA 21-1 immunoradiometric assay as a marker of lung cancer. Cancer Res. 1993, 53, 61-66. [PubMed]

48. Aisner, D.L.; Sams, S.B. The role of cytology specimens in molecular testing of solid tumors: Techniques, limitations, and opportunities. Diagn. Cytopathol. 2012, 40, 511-524. [CrossRef]

49. Greillier, L.; Baas, P.; Welch, J.J.; Hasan, B.; Passioukov, A. Biomarkers for malignant pleural mesothelioma. Mol. Diagn. Ther. 2008, 12, 375-390. [CrossRef]

50. Scherpereel, A.; Lee, Y.G. Biomarkers for mesothelioma. Curr. Opin. Pulm. Med. 2007, 13, 339-343. [CrossRef]

51. Park, E.-K.; Sandrini, A.; Yates, D.H.; Creaney, J.; Robinson, B.W.; Thomas, P.S.; Johnson, A.R. Soluble mesothelin-related protein in an asbestos-exposed population: The dust diseases board cohort study. Am. J. Resp. Crit. Care 2008, 178, 832-837. [CrossRef] [PubMed]

52. Shiomi, K.; Hagiwara, Y.; Sonoue, K.; Segawa, T.; Miyashita, K.; Maeda, M.; Izumi, H.; Masuda, K.; Hirabayashi, M.; Moroboshi, T. Sensitive and specific new enzyme-linked immunosorbent assay for N-ERC/mesothelin increases its potential as a useful serum tumor marker for mesothelioma. Clin. Cancer Res. 2008, 14, 1431-1437. [CrossRef]

53. Porcel, J.M.; Vives, M.; Esquerda, A.; Salud, A.; Pérez, B.; Rodríguez-Panadero, F. Use of a panel of tumor markers (carcinoembryonic antigen, cancer antigen 125, carbohydrate antigen 15-3, and cytokeratin 19 fragments) in pleural fluid for the differential diagnosis of benign and malignant effusions. Chest 2004, 126, 1757-1763. [CrossRef]

54. King, J.; Thatcher, N.; Pickering, C.; Hasleton, P.S. Sensitivity and specificity of immunohistochemical markers used in the diagnosis of epithelioid mesothelioma: A detailed systematic analysis using published data. Histopathology 2006, 48, 223-232. [CrossRef] [PubMed]

55. Homola, J.; Yee, S.S.; Gauglitz, G. Surface plasmon resonance sensors. Sens. Actuators B Chem. 1999, 54, 3-15. [CrossRef]

56. Sreekanth, K.V.; Alapan, Y.; ElKabbash, M.; Ilker, E.; Hinczewski, M.; Gurkan, U.A.; De Luca, A.; Strangi, G. Extreme sensitivity biosensing platform based on hyperbolic metamaterials. Nat. Mater. 2016, 15, 621-627. [CrossRef] [PubMed]

57. Ng, S.P.; Qiu, G.; Ding, N.; Lu, X.; Wu, C.M.L. Label-free detection of 3-nitro-l-tyrosine with nickel-doped graphene localized surface plasmon resonance biosensor. Biosens. Bioelectron. 2017, 89, 468-476. [CrossRef] [PubMed]

58. Otto, L.M.; Mohr, D.A.; Johnson, T.W.; Oh, S.H.; Lindquist, N.C. Polarization interferometry for real-time spectroscopic plasmonic sensing. Nanoscale 2015, 7, 4226-4233. [CrossRef]

59. Yesilkoy, F. Optical interrogation techniques for nanophotonic biochemical sensors. Sensors 2019, 19, 4287. [CrossRef]

60. Piliarik, M.; Homola, J. Surface plasmon resonance (SPR) sensors: Approaching their limits? Opt. Express 2009, 17, 16505-16517. [CrossRef] [PubMed]

61. Wang, X.; Jefferson, M.; Hobbs, P.C.; Risk, W.P.; Feller, B.E.; Miller, R.D.; Knoesen, A. Shot-noise limited detection for surface plasmon sensing. Opt. Express 2011, 19, 107-117. [CrossRef]

62. Liu, L.; Zhang, X.; Kenney, M.; Su, X.; Xu, N.; Ouyang, C.; Shi, Y.; Han, J.; Zhang, W.; Zhang, S. Broadband metasurfaces with simultaneous control of phase and amplitude. Adv. Mater. 2014, 26, 5031-5036. [CrossRef] [PubMed]

63. Wu, P.C.; Tsai, W.-Y.; Chen, W.T.; Huang, Y.-W.; Chen, T.-Y.; Chen, J.-W.; Liao, C.Y.; Chu, C.H.; Sun, G.; Tsai, D.P. Versatile polarization generation with an aluminum plasmonic metasurface. Nano Lett. 2017, 17, 445-452. [CrossRef] [PubMed]

64. Yu, N.; Genevet, P.; Kats, M.A.; Aieta, F.; Tetienne, J.-P.; Capasso, F.; Gaburro, Z. Light propagation with phase discontinuities: Generalized laws of reflection and refraction. Science 2011, 334, 333-337. [CrossRef]

65. Arbabi, A.; Arbabi, E.; Horie, Y.; Kamali, S.M.; Faraon, A. Planar metasurface retroreflector. Nat. Photonics 2017, 11, 415-420. [CrossRef]

66. Wang, S.; Wu, P.C.; Su, V.-C.; Lai, Y.-C.; Chu, C.H.; Chen, J.-W.; Lu, S.-H.; Chen, J.; Xu, B.; Kuan, C.-H. Broadband achromatic optical metasurface devices. Nat. Commun. 2017, 8, 187. [CrossRef]

67. Mueller, J.B.; Rubin, N.A.; Devlin, R.C.; Groever, B.; Capasso, F. Metasurface polarization optics: Independent phase control of arbitrary orthogonal states of polarization. Phys. Rev. Lett. 2017, 118, 113901. [CrossRef] [PubMed]

68. Chung, T.; Lee, S.-Y.; Song, E.Y.; Chun, H.; Lee, B. Plasmonic nanostructures for nano-scale bio-sensing. Sensors 2011, 11, 10907-10929. [CrossRef]

69. Roh, S.; Chung, T.; Lee, B. Overview of the characteristics of micro- and nano-structured surface plasmon resonance sensors. Sensors 2011, 11, 1565-1588. [CrossRef]

70. Chen, T.; Li, S.; Sun, H. Metamaterials application in sensing. Sensors 2012, 12, 2742-2765. [CrossRef] [PubMed]

71. Li, M.; Cushing, S.K.; Wu, N. Plasmon-enhanced optical sensors: A review. Analyst 2015, 140, 386-406. [CrossRef]

72. Zayats, A.V.; Smolyaninov, I.I. Near-field photonics: Surface plasmon polaritons and localized surface plasmons. J. Opt. A Pure Appl. Opt. 2003, 5, S16. [CrossRef]

73. Homola, J. Surface Plasmon Resonance-Based Sensors; Springer Science \& Business Media: Berlin, Germany, 2006 ; Volume 4.

74. Xu, Y.; Bai, P.; Zhou, X.; Akimov, Y.; Png, C.E.; Ang, L.K.; Knoll, W.; Wu, L. Optical refractive index sensors with plasmonic and photonic structures: Promising and inconvenient truth. Adv. Opt. Mater. 2019, 7, 1801433. [CrossRef]

75. Shrivastava, A.; Gupta, V.B. Methods for the determination of limit of detection and limit of quantitation of the analytical methods. Chron. Young Sci. 2011, 2, 21-25. [CrossRef] 
76. Zhu, J.; Wang, Z.; Lin, S.; Jiang, S.; Liu, X.; Guo, S. Low-cost flexible plasmonic nanobump metasurfaces for label-free sensing of serum tumor marker. Biosens. Bioelectron. 2020, 150, 111905. [CrossRef]

77. Im, H.; Shao, H.; Park, Y.I.; Peterson, V.M.; Castro, C.M.; Weissleder, R.; Lee, H. Label-free detection and molecular profiling of exosomes with a nano-plasmonic sensor. Nat. Biotechnol. 2014, 32, 490-495. [CrossRef]

78. Reddy, P.J.; Sadhu, S.; Ray, S.; Srivastava, S. Cancer biomarker detection by surface plasmon resonance biosensors. Clin. Lab. Med. 2012, 32, 47-72. [CrossRef] [PubMed]

79. Zhou, J.; Tao, F.; Zhu, J.; Lin, S.; Wang, Z.; Wang, X.; Ou, J.-Y.; Li, Y.; Liu, Q.H. Portable tumor biosensing of serum by plasmonic biochips in combination with nanoimprint and microfluidics. Nanophotonics 2019, 8, 307-316. [CrossRef]

80. Catalona, W.J.; Partin, A.W.; Slawin, K.M.; Brawer, M.K.; Flanigan, R.C.; Patel, A.; Richie, J.P.; DeKernion, J.B.; Walsh, P.C.; Scardino, P.T. Use of the percentage of free prostate-specific antigen to enhance differentiation of prostate cancer from benign prostatic disease: A prospective multicenter clinical trial. JAMA 1998, 279, 1542-1547. [CrossRef]

81. Damborska, D.; Bertok, T.; Dosekova, E.; Holazova, A.; Lorencova, L.; Kasak, P.; Tkac, J. Nanomaterial-based biosensors for detection of prostate specific antigen. Microchim. Acta 2017, 184, 3049-3067. [CrossRef]

82. Kim, W.T.; Yun, S.J.; Kim, W.-J. For physicians managing voiding dysfunction, improving the detection rate of early prostate cancer and discrimination from benign prostatic hyperplasia, in a molecular biomarker aspect. Int. Neurourol. J. 2019, 23, 5 . [CrossRef] [PubMed]

83. Khan, Y.; Li, A.; Chang, L.; Li, L.; Guo, L. Gold nano disks arrays for localized surface plasmon resonance-based detection of PSA cancer marker. Sens. Actuators B Chem. 2018, 255, 1298-1307. [CrossRef]

84. Sanders, M.; Lin, Y.; Wei, J.; Bono, T.; Lindquist, R.G. An enhanced LSPR fiber-optic nanoprobe for ultrasensitive detection of protein biomarkers. Biosens. Bioelectron. 2014, 61, 95-101. [CrossRef]

85. Rusling, J.F.; Kumar, C.V.; Gutkind, J.S.; Patel, V. Measurement of biomarker proteins for point-of-care early detection and monitoring of cancer. Analyst 2010, 135, 2496-2511. [CrossRef] [PubMed]

86. Couture, M.; Ray, K.K.; Poirier-Richard, H.-P.; Crofton, A.; Masson, J.-F. 96-well plasmonic sensing with nanohole arrays. ACS Sens. 2016, 1, 287-294. [CrossRef]

87. Li, W.; Qiu, Y.; Zhang, L.; Jiang, L.; Zhou, Z.; Chen, H.; Zhou, J. Aluminum nanopyramid array with tunable ultraviolet-visibleinfrared wavelength plasmon resonances for rapid detection of carbohydrate antigen 199. Biosens. Bioelectron. 2016, 79, 500-507. [CrossRef]

88. Shen, Y.; Zhou, J.; Liu, T.; Tao, Y.; Jiang, R.; Liu, M.; Xiao, G.; Zhu, J.; Zhou, Z.-K.; Wang, X. Plasmonic gold mushroom arrays with refractive index sensing figures of merit approaching the theoretical limit. Nat. Commun. 2013, 4, 2381. [CrossRef] [PubMed]

89. Predabon, S.M.; Buzzetti, P.H.; Visentainer, J.E.; Visentainer, J.V.; Radovanovic, E.; Monteiro, J.P.; Girotto, E.M. Detection of tumor necrosis factor-alpha cytokine from the blood serum of a rat infected with $\mathrm{Pb} 18$ by a gold nanohole array-based plasmonic biosensor. J. Nanophotonics. 2020, 14, 036004. [CrossRef]

90. Jiao, F.; Li, F.; Shen, J.; Guan, C.; Khan, S.A.; Wang, J.; Yang, Z.; Zhu, J. Wafer-Scale Flexible Plasmonic Metasurface with Passivated Aluminum Nanopillars for High-Sensitivity Immunosensors. Sens. Actuators B Chem. 2021, 344, 130170. [CrossRef]

91. Geng, Z.; Zhang, X.; Fan, Z.; Lv, X.; Chen, H. A route to terahertz metamaterial biosensor integrated with microfluidics for liver cancer biomarker testing in early stage. Sci. Rep. 2017, 7, 16378. [CrossRef] [PubMed]

92. Théry, C.; Ostrowski, M.; Segura, E. Membrane vesicles as conveyors of immune responses. Nat. Rev. Immunol. 2009, 9, 581-593. [CrossRef]

93. Vlassov, A.V.; Magdaleno, S.; Setterquist, R.; Conrad, R. Exosomes: Current knowledge of their composition, biological functions, and diagnostic and therapeutic potentials. Biochim. Biophys. Acta 2012, 1820, 940-948. [CrossRef]

94. Chin, L.K.; Son, T.; Hong, J.-S.; Liu, A.-Q.; Skog, J.; Castro, C.M.; Weissleder, R.; Lee, H.; Im, H. Plasmonic sensors for extracellular vesicle analysis: From scientific development to translational research. ACS Nano 2020, 14, 14528-14548. [CrossRef]

95. Park, J.; Im, H.; Hong, S.; Castro, C.M.; Weissleder, R.; Lee, H. Analyses of intravesicular exosomal proteins using a nano-plasmonic system. ACS Photonics 2018, 5, 487-494. [CrossRef] [PubMed]

96. Yang, K.S.; Im, H.; Hong, S.; Pergolini, I.; Del Castillo, A.F.; Wang, R.; Clardy, S.; Huang, C.-H.; Pille, C.; Ferrone, S. Multiparametric plasma EV profiling facilitates diagnosis of pancreatic malignancy. Sci. Transl. Med. 2017, 9, eaal3226. [CrossRef] [PubMed]

97. Lim, C.Z.; Zhang, Y.; Chen, Y.; Zhao, H.; Stephenson, M.C.; Ho, N.R.; Chen, Y.; Chung, J.; Reilhac, A.; Loh, T.P. Subtyping of circulating exosome-bound amyloid $\beta$ reflects brain plaque deposition. Nat. Commun. 2019, 10, 1144. [CrossRef]

98. Yang, Q.; Cheng, L.; Hu, L.; Lou, D.; Zhang, T.; Li, J.; Zhu, Q.; Liu, F. An integrative microfluidic device for isolation and ultrasensitive detection of lung cancer-specific exosomes from patient urine. Biosens. Bioelectron. 2020, 163, 112290. [CrossRef]

99. Zhu, S.; Li, H.; Yang, M.; Pang, S.W. Highly sensitive detection of exosomes by 3D plasmonic photonic crystal biosensor. Nanoscale 2018, 10, 19927-19936. [CrossRef]

100. Hackett, L.P.; Ameen, A.; Li, W.; Dar, F.K.; Goddard, L.L.; Liu, G.L. Spectrometer-free plasmonic biosensing with metal-insulatormetal nanocup arrays. ACS Sens. 2018, 3, 290-298. [CrossRef] [PubMed]

101. Yavas, O.; Svedendahl, M.; Dobosz, P.; Sanz, V.; Quidant, R. On-a-chip biosensing based on all-dielectric nanoresonators. Nano Lett. 2017, 17, 4421-4426. [CrossRef]

102. Wu, F.; Zhao, S.; Yu, B.; Chen, Y.-M.; Wang, W.; Song, Z.-G.; Hu, Y.; Tao, Z.-W.; Tian, J.-H.; Pei, Y.-Y. A new coronavirus associated with human respiratory disease in China. Nature 2020, 579, 265-269. [CrossRef] 
103. Muruato, A.E.; Fontes-Garfias, C.R.; Ren, P.; Garcia-Blanco, M.A.; Menachery, V.D.; Xie, X.; Shi, P.-Y. A high-throughput neutralizing antibody assay for COVID-19 diagnosis and vaccine evaluation. Nat. Commun. 2020, 11, 4059. [CrossRef]

104. Ai, J.-W.; Zhang, H.-C.; Xu, T.; Wu, J.; Zhu, M.; Yu, Y.-Q.; Zhang, H.-Y.; Li, Y.; Zhou, X.; Shen, Z. Optimizing diagnostic strategy for novel coronavirus pneumonia, a multi-center study in Eastern China. MedRxiv 2020. [CrossRef]

105. Baek, Y.H.; Um, J.; Antigua, K.J.C.; Park, J.-H.; Kim, Y.; Oh, S.; Kim, Y.-i.; Choi, W.-S.; Kim, S.G.; Jeong, J.H. Development of a reverse transcription-loop-mediated isothermal amplification as a rapid early-detection method for novel SARS-CoV-2. Emerg. Microbes Infect. 2020, 9, 998-1007. [CrossRef]

106. Haveri, A.; Smura, T.; Kuivanen, S.; Österlund, P.; Hepojoki, J.; Ikonen, N.; Pitkäpaasi, M.; Blomqvist, S.; Rönkkö, E.; Kantele, A. Serological and molecular findings during SARS-CoV-2 infection: The first case study in Finland, January to February 2020. Eurosurveillance 2020, 25, 2000266. [CrossRef] [PubMed]

107. Santiago, I. Trends and innovations in biosensors for COVID-19 mass testing. ChemBioChem 2020, 21, 2880. [CrossRef] [PubMed]

108. Udugama, B.; Kadhiresan, P.; Kozlowski, H.N.; Malekjahani, A.; Osborne, M.; Li, V.Y.; Chen, H.; Mubareka, S.; Gubbay, J.B.; Chan, W.C. Diagnosing COVID-19: The disease and tools for detection. ACS Nano 2020, 14, 3822-3835. [CrossRef]

109. Amanat, F.; Stadlbauer, D.; Strohmeier, S.; Nguyen, T.H.; Chromikova, V.; McMahon, M.; Jiang, K.; Arunkumar, G.A.; Jurczyszak, D.; Polanco, J. A serological assay to detect SARS-CoV-2 seroconversion in humans. Nat. Med. 2020, 26, 1033-1036. [CrossRef] [PubMed]

110. Guan, M.; Chen, H.Y.; Foo, S.Y.; Tan, Y.-J.; Goh, P.-Y.; Wee, S.H. Recombinant protein-based enzyme-linked immunosorbent assay and immunochromatographic tests for detection of immunoglobulin G antibodies to severe acute respiratory syndrome (SARS) coronavirus in SARS patients. Clin. Diagn. Lab. Immunol. 2004, 11, 287-291. [CrossRef]

111. Day, M. COVID-19: Identifying and isolating asymptomatic people helped eliminate virus in Italian village. BMJ Br. Med. J. 2020, 368, m1165. [CrossRef]

112. Du, Z.; Zhu, F.; Guo, F.; Yang, B.; Wang, T. Detection of antibodies against SARS-CoV-2 in patients with COVID-19. J. Med. Virol. 2020, 92, 1735-1738. [CrossRef]

113. Lee, C.Y.-P.; Lin, R.T.; Renia, L.; Ng, L.F. Serological approaches for COVID-19: Epidemiologic perspective on surveillance and control. Front. Immun. 2020, 11, 879. [CrossRef] [PubMed]

114. Li, R.; Pei, S.; Chen, B.; Song, Y.; Zhang, T.; Yang, W.; Shaman, J. Substantial undocumented infection facilitates the rapid dissemination of novel coronavirus (SARS-CoV-2). Science 2020, 368, 489-493. [CrossRef]

115. Corman, V.M.; Landt, O.; Kaiser, M.; Molenkamp, R.; Meijer, A.; Chu, D.K.; Bleicker, T.; Brünink, S.; Schneider, J.; Schmidt, M.L. Detection of 2019 novel coronavirus (2019-nCoV) by real-time RT-PCR. Eurosurveillance 2020, 25, 2000045. [CrossRef]

116. Huang, Z.; Tian, D.; Liu, Y.; Lin, Z.; Lyon, C.J.; Lai, W.; Fusco, D.; Drouin, A.; Yin, X.; Hu, T. Ultra-sensitive and high-throughput CRISPR-p owered COVID-19 diagnosis. Biosens. Bioelectron. 2020, 164, 112316. [CrossRef]

117. Baraniuk, C. COVID-19 antibody tests: A briefing. BMJ 2020, 369, m2284. [CrossRef]

118. La Marca, A.; Capuzzo, M.; Paglia, T.; Roli, L.; Trenti, T.; Nelson, S.M. Testing for SARS-CoV-2 (COVID-19): A systematic review and clinical guide to molecular and serological in-vitro diagnostic assays. Reprod. Biomed. Online 2020, 41, 483-499. [CrossRef]

119. Krammer, F.; Simon, V. Serology assays to manage COVID-19. Science 2020, 368, 1060-1061. [CrossRef]

120. Chu, D.K.; Pan, Y.; Cheng, S.M.; Hui, K.P.; Krishnan, P.; Liu, Y.; Ng, D.Y.; Wan, C.K.; Yang, P.; Wang, Q. Molecular diagnosis of a novel coronavirus (2019-nCoV) causing an outbreak of pneumonia. Clin. Chem. 2020, 66, 549-555. [CrossRef] [PubMed]

121. Dang, T.; Hu, W.; Zhang, W.; Song, Z.; Wang, Y.; Chen, M.; Xu, H.; Liu, G.L. Protein binding kinetics quantification via coupled plasmonic-photonic resonance nanosensors in generic microplate reader. Biosens. Bioelectron. 2019, 142, 111494. [CrossRef] [PubMed]

122. Bhalla, N.; Pan, Y.; Yang, Z.; Payam, A.F. Opportunities and challenges for biosensors and nanoscale analytical tools for pandemics: COVID-19. ACS Nano 2020, 14, 7783-7807. [CrossRef]

123. Carter, L.J.; Garner, L.V.; Smoot, J.W.; Li, Y.; Zhou, Q.; Saveson, C.J.; Sasso, J.M.; Gregg, A.C.; Soares, D.J.; Beskid, T.R. Assay techniques and test development for COVID-19 diagnosis. ACS Cent Sci. 2020, 6, 591-605. [CrossRef] [PubMed]

124. Choi, J.R. Development of point-of-care biosensors for COVID-19. Front. Chem. 2020, 8, 517. [CrossRef]

125. Mavrikou, S.; Moschopoulou, G.; Tsekouras, V.; Kintzios, S. Development of a portable, ultra-rapid and ultra-sensitive cell-based biosensor for the direct detection of the SARS-CoV-2 S1 spike protein antigen. Sensors 2020, 20, 3121. [CrossRef] [PubMed]

126. Vemula, S.V.; Zhao, J.; Liu, J.; Wang, X.; Biswas, S.; Hewlett, I. Current approaches for diagnosis of influenza virus infections in humans. Viruses 2016, 8, 96. [CrossRef]

127. Liu, R.; Han, H.; Liu, F.; Lv, Z.; Wu, K.; Liu, Y.; Feng, Y.; Zhu, C. Positive rate of RT-PCR detection of SARS-CoV-2 infection in 4880 cases from one hospital in Wuhan, China, from Jan to Feb 2020. Clin. Chim. Acta 2020, 505, 172-175. [CrossRef]

128. Hassan, M.M.; Sium, F.S.; Islam, F.; Choudhury, S.M. A review on plasmonic and metamaterial based biosensing platforms for virus detection. Sens. Bio-Sens. Res. 2021, 33, 100429. [CrossRef]

129. Nolan, T.; Hands, R.E.; Bustin, S.A. Quantification of mRNA using real-time RT-PCR. Nat. Protoc. 2006, 1, 1559-1582. [CrossRef]

130. Smyrlaki, I.; Ekman, M.; Lentini, A.; de Sousa, N.R.; Papanicolaou, N.; Vondracek, M.; Aarum, J.; Safari, H.; Muradrasoli, S.; Rothfuchs, A.G. Massive and rapid COVID-19 testing is feasible by extraction-free SARS-CoV-2 RT-PCR. Nat. Commun. 2020, 11, 4812. [CrossRef] [PubMed]

131. Bastos, M.L.; Tavaziva, G.; Abidi, S.K.; Campbell, J.R.; Haraoui, L.-P.; Johnston, J.C.; Lan, Z.; Law, S.; MacLean, E.; Trajman, A Diagnostic accuracy of serological tests for COVID-19: Systematic review and meta-analysis. BMJ 2020, 370, m2516. [CrossRef] 
132. Yüce, M.; Filiztekin, E.; Özkaya, K.G. COVID-19 diagnosis-A review of current methods. Biosens. Bioelectron. 2020, $172,112752$. [CrossRef]

133. Soh, J.H.; Chan, H.-M.; Ying, J.Y. Strategies for developing sensitive and specific nanoparticle-based lateral flow assays as point-of-care diagnostic device. Nano Today 2020, 30, 100831. [CrossRef]

134. Lin, D.; Liu, L.; Zhang, M.; Hu, Y.; Yang, Q.; Guo, J.; Dai, Y.; Xu, Y.; Cai, Y.; Chen, X. Evaluations of the serological test in the diagnosis of 2019 novel coronavirus (SARS-CoV-2) infections during the COVID-19 outbreak. Eur. J. Clin. Microbiol. 2020, 39, 2271-2277. [CrossRef] [PubMed]

135. Sakamoto, S.; Putalun, W.; Vimolmangkang, S.; Phoolcharoen, W.; Shoyama, Y.; Tanaka, H.; Morimoto, S. Enzyme-linked immunosorbent assay for the quantitative/qualitative analysis of plant secondary metabolites. J. Nat. Med. 2018, 72, 32-42. [CrossRef] [PubMed]

136. Souf, S. Recent advances in diagnostic testing for viral infections. Biosci. Horiz. Int. J. Stud. Res. 2016, 9, hzw010.

137. Soler, M.; Estevez, M.C.; Cardenosa-Rubio, M.; Astua, A.; Lechuga, L.M. How nanophotonic label-free biosensors can contribute to rapid and massive diagnostics of respiratory virus infections: COVID-19 case. ACS Sens. 2020, 5, 2663-2678. [CrossRef]

138. Zanchetta, G.; Lanfranco, R.; Giavazzi, F.; Bellini, T.; Buscaglia, M. Emerging applications of label-free optical biosensors. Nanophotonics 2017, 6, 627-645. [CrossRef]

139. Lopez, G.A.; Estevez, M.-C.; Soler, M.; Lechuga, L.M. Recent advances in nanoplasmonic biosensors: Applications and lab-on-achip integration. Nanophotonics 2017, 6, 123-136. [CrossRef]

140. Huang, L.; Ding, L.; Zhou, J.; Chen, S.; Chen, F.; Zhao, C.; Xu, J.; Hu, W.; Ji, J.; Xu, H. One-step rapid quantification of SARS-CoV-2 virus particles via low-cost nanoplasmonic sensors in generic microplate reader and point-of-care device. Biosens. Bioelectron. 2021, 171, 112685. [CrossRef] [PubMed]

141. Funari, R.; Chu, K.-Y.; Shen, A.Q. Detection of antibodies against SARS-CoV-2 spike protein by gold nanospikes in an optomicrofluidic chip. Biosens. Bioelectron. 2020, 169, 112578. [CrossRef]

142. Yanik, A.A.; Huang, M.; Kamohara, O.; Artar, A.; Geisbert, T.W.; Connor, J.H.; Altug, H. An optofluidic nanoplasmonic biosensor for direct detection of live viruses from biological media. Nano Lett. 2010, 10, 4962-4969. [CrossRef]

143. Qiu, G.; Gai, Z.; Tao, Y.; Schmitt, J.; Kullak-Ublick, G.A.; Wang, J. Dual-functional plasmonic photothermal biosensors for highly accurate severe acute respiratory syndrome coronavirus 2 detection. ACS Nano 2020, 14, 5268-5277. [CrossRef]

144. Qiu, G.; Gai, Z.; Saleh, L.; Tang, J.; Gui, T.; Kullak-Ublick, G.A.; Wang, J. Thermoplasmonic-assisted cyclic cleavage amplification for self-validating plasmonic detection of SARS-CoV-2. ACS Nano 2021, 15, 7536-7546. [CrossRef]

145. Das, C.M.; Guo, Y.; Yang, G.; Kang, L.; Xu, G.; Ho, H.P.; Yong, K.T. Gold Nanorod Assisted Enhanced Plasmonic Detection Scheme of COVID-19 SARS-CoV-2 Spike Protein. Adv. Theor. Simul. 2020, 3, 2000185. [CrossRef] [PubMed]

146. Moitra, P.; Alafeef, M.; Dighe, K.; Frieman, M.B.; Pan, D. Selective naked-eye detection of SARS-CoV-2 mediated by N gene targeted antisense oligonucleotide capped plasmonic nanoparticles. ACS Nano 2020, 14, 7617-7627. [CrossRef]

147. Ahmadivand, A.; Gerislioglu, B.; Ramezani, Z.; Kaushik, A.; Manickam, P.; Ghoreishi, S.A. Functionalized terahertz plasmonic metasensors: Femtomolar-level detection of SARS-CoV-2 spike proteins. Biosens. Bioelectron. 2021, 177, 112971. [CrossRef] [PubMed]

148. Cheong, J.; Yu, H.; Lee, C.Y.; Lee, J.-u.; Choi, H.-J.; Lee, J.-H.; Lee, H.; Cheon, J. Fast detection of SARS-CoV-2 RNA via the integration of plasmonic thermocycling and fluorescence detection in a portable device. Nat. Biomed. Eng. 2020, 4, 1159-1167. [CrossRef] [PubMed]

149. Gao, Y.; Han, Y.; Wang, C.; Qiang, L.; Gao, J.; Wang, Y.; Liu, H.; Han, L.; Zhang, Y. Rapid and sensitive triple-mode detection of causative SARS-CoV-2 virus specific genes through interaction between genes and nanoparticles. Anal. Chim. Acta 2021, 1154, 338330. [CrossRef]

150. Hesselink, L.; Padhy, P.; Zaman, M.A.; Wu, M.; Jensen, M.A. In Trapping and manipulation on a chip: From subwavelength particle manipulation to chemical synthesis. In Proceedings of the Optical Trapping and Optical Micromanipulation XVIII, San Diego, CA, USA, 1-5 August 2021; p. 117981P.

151. Zaman, M.A.; Padhy, P.; Hesselink, L. Near-field optical trapping in a non-conservative force field. Sci. Rep. 2019, 9, 649. [CrossRef]

152. Padhy, P.; Zaman, M.A.; Hesselink, L. In-plane near-field optical barrier on a chip. Opt. Lett. 2019, 44, 2061-2064. [CrossRef]

153. Zaman, M.A.; Padhy, P.; Hesselink, L. Fokker-Planck analysis of optical near-field traps. Sci. Rep. 2019, 9, 9557. [CrossRef]

154. Wen, D.; Crozier, K.B. Metasurfaces 2.0: Laser-integrated and with vector field control. APL Photonics 2021, 6, 080902. [CrossRef]

155. Ye, M.; Zha, J.; Tan, C.; Crozier, K.B. Graphene-based mid-infrared photodetectors using metamaterials and related concepts. Appl. Phys. Rev. 2021, 8, 031303. [CrossRef]

156. Li, N.; Cadusch, J.; Liu, A.; Barlow, A.J.; Roberts, A.; Crozier, K.B. Algorithm-Designed Plasmonic Nanotweezers: Quantitative Comparison by Theory, Cathodoluminescence, and Nanoparticle Trapping. Adv. Opt. Mater. 2021, 9, 2100758. [CrossRef]

157. Oh, S.H.; Altug, H.; Jin, X.; Low, T.; Koester, S.J.; Ivanov, A.P.; Edel, J.B.; Avouris, P.; Strano, M.S. Nanophotonic biosensors harnessing van der Waals materials. Nat. Commun. 2021, 12, 3824. [CrossRef]

158. Wang, X.; Jian, J.; Diaz-Amaya, S.; Kumah, C.E.; Lu, P.; Huang, J.; Lim, D.G.; Pol, V.G.; Youngblood, J.P.; Boltasseva, A. Hybrid plasmonic Au-TiN vertically aligned nanocomposites: A nanoscale platform towards tunable optical sensing. Nanoscale Adv. 2019, 1, 1045-1054. [CrossRef] 
159. Choudhury, S.M.; Wang, D.; Chaudhuri, K.; DeVault, C.; Kildishev, A.V.; Boltasseva, A.; Shalaev, V.M. Material platforms for optical metasurfaces. Nanophotonics 2018, 7, 959-987. [CrossRef]

160. Guo, W.-P.; Mishra, R.; Cheng, C.-W.; Wu, B.-H.; Chen, L.-J.; Lin, M.-T.; Gwo, S. Titanium nitride epitaxial films as a plasmonic material platform: Alternative to gold. ACS Photonics 2019, 6, 1848-1854. [CrossRef]

161. Rastgordani, A.; Kashani, Z.G. Robust design method for metasurface high-sensitivity sensors and absorbers. J. Opt. Soc. Am. B 2020, 37, 2006-2011. [CrossRef]

162. Wang, Y.; Yu, J.; Mao, Y.F.; Chen, J.; Wang, S.; Chen, H.Z.; Zhang, Y.; Wang, S.Y.; Chen, X.; Li, T.; et al. Stable, high-performance sodium-based plasmonic devices in the near infrared. Nature 2020, 581, 401-405. [CrossRef]

163. Whitesides, G.M.; Grzybowski, B. Self-assembly at all scales. Science 2002, 295, 2418-2421. [CrossRef] [PubMed]

164. Li, N.; Tittl, A.; Yue, S.; Giessen, H.; Song, C.; Ding, B.; Liu, N. DNA-assembled bimetallic plasmonic nanosensors. Light Sci. Appl. 2014, 3, e226. [CrossRef]

165. Malkiel, I.; Mrejen, M.; Nagler, A.; Arieli, U.; Wolf, L.; Suchowski, H. Plasmonic nanostructure design and characterization via deep learning. Light Sci. Appl. 2018, 7, 8074. [CrossRef]

166. Li, X.; Shu, J.; Gu, W.; Gao, L. Deep neural network for plasmonic sensor modeling. Opt. Mater. Express 2019, 9, 3857-3862. [CrossRef]

167. Tittl, A.; John-Herpin, A.; Leitis, A.; Arvelo, E.R.; Altug, H. Metasurface-based molecular biosensing aided by artificial intelligence. Angew. Chem. Int. Ed. 2019, 58, 14810-14822. [CrossRef] [PubMed]

168. Gomes, J.C.M.; Souza, L.C.; Oliveira, L.C. SmartSPR sensor: Machine learning approaches to create intelligent surface plasmon based sensors. Biosens. Bioelectron. 2021, 172, 112760. [CrossRef] [PubMed] 